\title{
BMJ Open Analytical observational study evaluating global pandemic preparedness and the effectiveness of early COVID-19 responses in Ethiopia, Nigeria, Singapore, South Korea, Sweden, Taiwan, UK and USA
}

Alexandra Nikolaeva (D), Jenny Versnel

To cite: Nikolaeva A, Versnel J. Analytical observational study evaluating global pandemic preparedness and the effectiveness of early COVID-19 responses in Ethiopia, Nigeria, Singapore, South Korea, Sweden, Taiwan, UK and USA. BMJ Open 2022;12:e053374. doi:10.1136/ bmjopen-2021-053374

- Prepublication history for this paper is available online. To view these files, please visit the journal online (http://dx.doi. org/10.1136/bmjopen-2021 053374).

Received 23 May 2021 Accepted 17 December 2021

A) Check for updates

(c) Author(s) (or their employer(s)) 2022. Re-use permitted under CC BY-NC. No commercial re-use. See rights and permissions. Published by BMJ.

Academy of Therapeutic Sciences, Faculty of Biology, University of Cambridge, Cambridge, UK

Correspondence to Alexandra Nikolaeva; alexnicolaeva@gmail.com

\section{ABSTRACT}

Objectives An analysis of early country-specific COVID-19 strategies and the impact of policies, healthcare resources and cultural influences on their effectiveness.

Design Analytical observational study.

Setting USA, UK, Sweden, South Korea, Singapore, Taiwan, Ethiopia and Nigeria.

Main outcome measures 0xCGRT indices were used to quantify variations in governments' responses, and effectiveness was measured by the number of deaths as a proportion of the population. Hofstede's cultural dimensions, and the availability of healthcare resources, were analysed for their potential impact on effectiveness. Results Effective strategies reflect factors such as speed of governmental intervention, cultural norms, population demographics and available resources. While biases, confounders and lack of data at the beginning of the pandemic make inferences challenging, publicly available data suggest that South Korea, Singapore and Taiwan were most successful through rapid identification and isolation of cases, and effective contact tracing systems.

Conclusion The rapid spread of the highly transmissible SARS-CoV-2 virus took many countries by surprise and the delayed global response contributed to the severity of the COVID-19 pandemic. The speed at which strategies were implemented is highly correlated to the number of deaths. Factors such as cultural norms and healthcare resources impact effectiveness significantly, implying that implementation of a global 'one size fits all' approach is challenging. Global preparedness should focus on effective surveillance and preparedness strategies to enable timely identification and containment of future threats.

\section{INTRODUCTION}

COVID-19 is an acute respiratory disease caused by a novel $\beta$-coronavirus strain (SARSCoV-2), first identified in Wuhan. What started as a local outbreak in Hubei Province in China rapidly escalated to a global emergency on 30 January 2020 and then into the pandemic declared by the WHO on
Strengths and limitations of this study

- Strengths of this study include evaluation of factors that influenced the early spread of the pandemic including Hofstede's cultural dimensions and quantitative analysis of the timings of implementation of control strategies and the proportion of Gross Domestic Product (GDP) spent on healthcare as a measure of effectiveness in controlling the spread of SARS-CoV-2.

- Effectiveness of strategies was evaluated from multiple angles using OxCGRT indices, deaths to population proportions and non-linear regression analysis of total number of COVID-19 related deaths in the first 6 months of the pandemic.

- Comparison is limited to eight countries and represents data from 21 January to 13 June 2020; as a result of this time period, the selection of countries was limited to those with WHO reported COVID-19 death data.

- Analysis based on publicly available data; accuracy is therefore dependent on transparency and hence limited.

- There is little discussion on the impact of factors such as biological background, age, comorbidities and the political setting, as their impact on COVID-19 related deaths was not well understood at the start of the pandemic.

11 March. ${ }^{1-3}$ Almost all countries have been affected, with $>310$ million identified cases and $>5.5$ million associated deaths recorded to date.

At the time of the COVID-19 pandemic announcement, there were no WHO-specific guidelines, variability of resources to tackle the virus, little understanding of the biology of the disease and a lack of conclusive data to enable countries to formulate strategies. Since the first few weeks of a pandemic are 
critical in terms of controlling exponential spread, it is particularly important to identify the factors that could have reduced the occurrence of COVID-19 outbreaks and prevent transmission. Analysis of the most effective early strategies and barriers to their implementation enable evaluation of the feasibility of implementing global pandemic strategies once a pandemic has been declared.

Some countries have been disproportionally affected, and this research aims to identify some of the factors that influenced its spread, and strategies were implemented early in the pandemic that were most effective in bringing it under control.

\section{Prevention prior to the spread}

Back in the early 2000s, the WHO recommended a global joint approach covering diagnosis, monitoring, data sharing, surveillance systems, training, interventions and rapid delivery of services to handle public health events and emergencies that have the potential to cross borders. After the SARS pandemics in 2005, 196 countries agreed to the new framework of International Health Regulations (IHR) to work together to prevent and control global health threats while protecting international travel and trade. ${ }^{4}$ In 2014, only 64 countries were reported to have fully achieved the core capacities, meaning that nearly $70 \%$ of the world was unprepared effectively to assess, detect, report and respond to potential public health threats. However, adherence to implementation of IHRs does not necessarily equate to countries being well prepared for COVID-19. The UK and Sweden scored 100 out of 100 on 'C3-Zoonotic Events and Human-animal Interface' indicators in 2019 and 2020, while their actual response to COVID-19 was not as successful as countries such as Singapore that scored lower on these indicators. ${ }^{5}$

Geographic spread of an infectious disease can be mapped, and spatial models were built based on ecological drivers of transmission to understand subsequently the dynamic global risk of the virus. ${ }^{6}$ Identification and control of human transmission clusters or surveillance of cases in contact with a natural reservoir is one way of dealing with the outbreak. For even earlier viral outbreak prevention, searching for and monitoring reservoirs, building up surveillance programmes and mathematical models can be used to forecast spread. Spatiotemporal analyses of pathogen genomes is another method of mapping and allows for the prediction of viral lineage exchange. Additionally, phylogenetic tools can aid the characterisation of viral introductions that lead to disease transmission in a novel location. Research groups sample wildlife populations and track animals' behaviour globally to understand patterns of viral diversity and determine cross-species transmission. ${ }^{7}$

Nowadays, the WHO collects and analyses influenza surveillance data globally to predict the selection of specific strains for vaccine production. ${ }^{8}$ Additionally, many academic researchers focus on predictions of influenza antigenic variation based on quantitative analyses of genetic and other types of data available. ${ }^{9}$ Problematically for rarely occurring viruses like coronaviruses, there is a lack of data to make such predictions.

A proactive global approach is required to reduce the potential for future pandemics. Globally, governments need to work together to put in place monitoring and surveillance schemes and have updated pandemic preparedness plans.

\section{Selected countries responses to the pandemic}

Countries reacted to the pandemic with varying strategies, and many differed in terms of their speed of implementation. ${ }^{10}$ At the start of the pandemic, the WHO reported limited COVID-19 infection and death data, thereby narrowing the selection of countries to analyse. To evaluate the most effective strategies, eight countries with different approaches were chosen: USA, UK, Sweden, Singapore, South Korea, Taiwan, Ethiopia and Nigeria.

The USA and the UK showed delayed responses to the pandemic, and both lie in the top 5 for having the highest number of deaths during the first half of 2020 . When policies were implemented, they were less onerus compared with many countries, with few consequences for not adhering to rules.

Sweden initially took a 'herd immunity' approach, ${ }^{11}$ with the government believing lockdown should be voluntary. By keeping schools open and having few restrictions in place, they believed this would provide a more effective and sustainable approach. ${ }^{12}$ While initially it appeared to be effective, at the end of 2020, Sweden had higher fatality rates than neighbouring countries and the USA and failed to achieve herd immunity. ${ }^{13}$

Asian countries including China, South Korea, Singapore and Taiwan reacted speedily, adopting strategies that, while being based on available data, appeared to be remarkably successful. ${ }^{14}$ They also placed an emphasis on collecting detailed data and widely disseminating accurate real-time information on mass media and technology platforms. In China, severe restrictions and quarantine were put in place, including shutting down entire cities and preventing all travel. In South Korea, the main strategy was an active, widespread and free thermal test screening for travellers, symptomatic individuals and case contacts. Similar to many other countries, their government banned large gatherings, closed schools and recommended remote working. While there were no lockdown or movement restrictions, everyone infected had to undergo compulsory government-tracked selfquarantine, with strict punishments in force. Singapore adopted a containment strategy to prevent widespread community transmission. Surveillance systems to identify potential cases and contacts, laboratory testing and diagnostic capacities were implemented and reinforced early on, while travellers were controlled selectively. Similarly to South Korea, the Singaporean government put effort into widely disseminating updated information on COVID-19 and promoting regular assemblies of regional health system managers, hospital and ministry of health bodies. Taiwan is the country that was estimated to be the 
most badly affected by COVID-19 due to its proximity to China, but their strategy was perhaps the most proactive and effective in the world. Following the SARS outbreak, the National Health Command Centre (NHCC) was established to manage disasters. For example, the Central Epidemic Division of NHCC introduced an immediate inspection of all passenger planes coming from Wuhan from 31 December 2019 onwards and banned all Wuhan residents after 23 January 2020. Taiwan's government claimed to stockpile personal protective equipment (PPE), stopped export and encouraged N95 mask production, initiated PPE distribution and resources allocation, promoted advancements in case identification technologies, enforced proactive identification of all patients and those with severe respiratory syndromes, set quarantining of potential cases and tracked down and mapped infected people. All of the above-mentioned countries have well-established economies with relatively high Gross Domestic Product (GDP) values. Given this is not the case for developing countries, implementing strict lockdowns, stockpiling resources and developing effective track and trace programmes is considerably more challenging.

There are, however, exceptions: Ethiopia initiated strict passenger screenings in January 2020 and house-to-house screenings of more than 40 million people. Moreover, a strict regime of isolation and compulsory quarantine with rigorous tracing was introduced in February. These responses were well ahead of some developed countries and were scaled up by mid-March, with campaigns to raise public awareness of COVID-19 and how to prevent the spread. Finally, a state of emergency was declared in April $2020 .{ }^{15}$ Compared with other countries cited, Ethiopia has extremely low resources, but if the data are accurate, their response was more successful than the majority of developed countries. Like Nigeria and other developing countries, the Ethiopian government struggled with providing sufficient tests and treatments. The Nigerian strategy was less effective: similar to many other African governments, Nigeria implemented a lockdown that encompassed self-isolation of sick people and social distancing, while 'shielding' individuals with high-risk of COVID-19 consequences. ${ }^{16}$ To mitigate economic consequences of a full lockdown, the Nigerian government emphasised communication of the importance of hygiene, social distancing and avoidance of social gatherings or travel. ${ }^{17}$

\section{METHODS}

Countries were selected for further analysis based on the different nature and varying outcomes of their strategies. GraphPad Prism V.8 was used for statistical analysis and visual representation of the extracted data. All analyses were performed for the first half a year into the COVID-19 spread, that is, the period from 21 January to 13 June 2020.

A number of online resources were researched in order to construct a response timeline for each of the eight countries, which compares the outbreak announcement, first COVID-19 case and first death caused by the virus (figure 1). ${ }^{18-36}$

Variations in government responses to COVID-19 was quantified using OxCGRT — a systematic way of tracking government policies and responses to COVID-19 over time. ${ }^{37}$ Tracker data were extracted from the OxCGRT website and visualised to create line and violin plots. Three different graphs (figure 2A) were created to analyse changes in Stringency Index (based on public information campaign index, school/workspace/public transport closures and 'lockdown' restrictions such as restrictions on gatherings, internal and international travel); Containment and Health Index (based on the same indicators as Stringency Index, and measures such as contact tracing index, facial coverings and testing policy); and government response (based on the same indicators as Containment and Health Index and measures of economic response as income support and debt/contract relief for households). Index values are within a range of $0-100$, where 0 is the absence of response and 100 is the strictest measures implementation. Method of the index's calculation is based on formulas comprising several indicators. Three violin plots (figure 2B) were created from the OxCGRT tracker data. Frequency distribution of each of the indices in the period of 21 January-13 June 2020 is represented by median values and kernel density. Index values range from 0 representing limitation or absence of policy to 4 representing maximum effort and adherence. OxCGRT is one of the few metrics quantifying governmental responses early on in the pandemic. We hypothesised that contact tracing, increased testing and accurate, timely information and campaigning were the key strategies for successful national mitigation of the pandemic.

Death rates and populations rounded to the nearest thousand were used to analyse the consequences and outcomes of strategies and speed of their implementations (figure 3A,B and C). ${ }^{1} 839$ Quantitative graphic analysis was performed from 21 January 2020 to 13 June 2020, where populations of each country was defined by the number of people as of 13 June 2020. Although impacted by confounders, death rates were chosen, as it is a high impact measure and arguably the most effective estimate to be used at the early stages of the pandemic when biology of the disease is not understood and no universal testing is equally available to all populations. Deaths per capita and as population proportions were used as better estimates than absolute differences for comparisons between separate countries. Population proportion deaths from COVID-19, 50 days after the first reported death, were calculated and compared between selected countries (figure 3B).

To quantify the effectiveness of strategies further, data based on cumulative COVID-19 death cases 50 days after first case appearance (figure 3C) were analysed to estimate the degree of exponential growth within the total number of cases. Exponential growth equation using Gaussian function with 95\% CI was used for nonlinear regression curve fit modelling. Using this method, the 


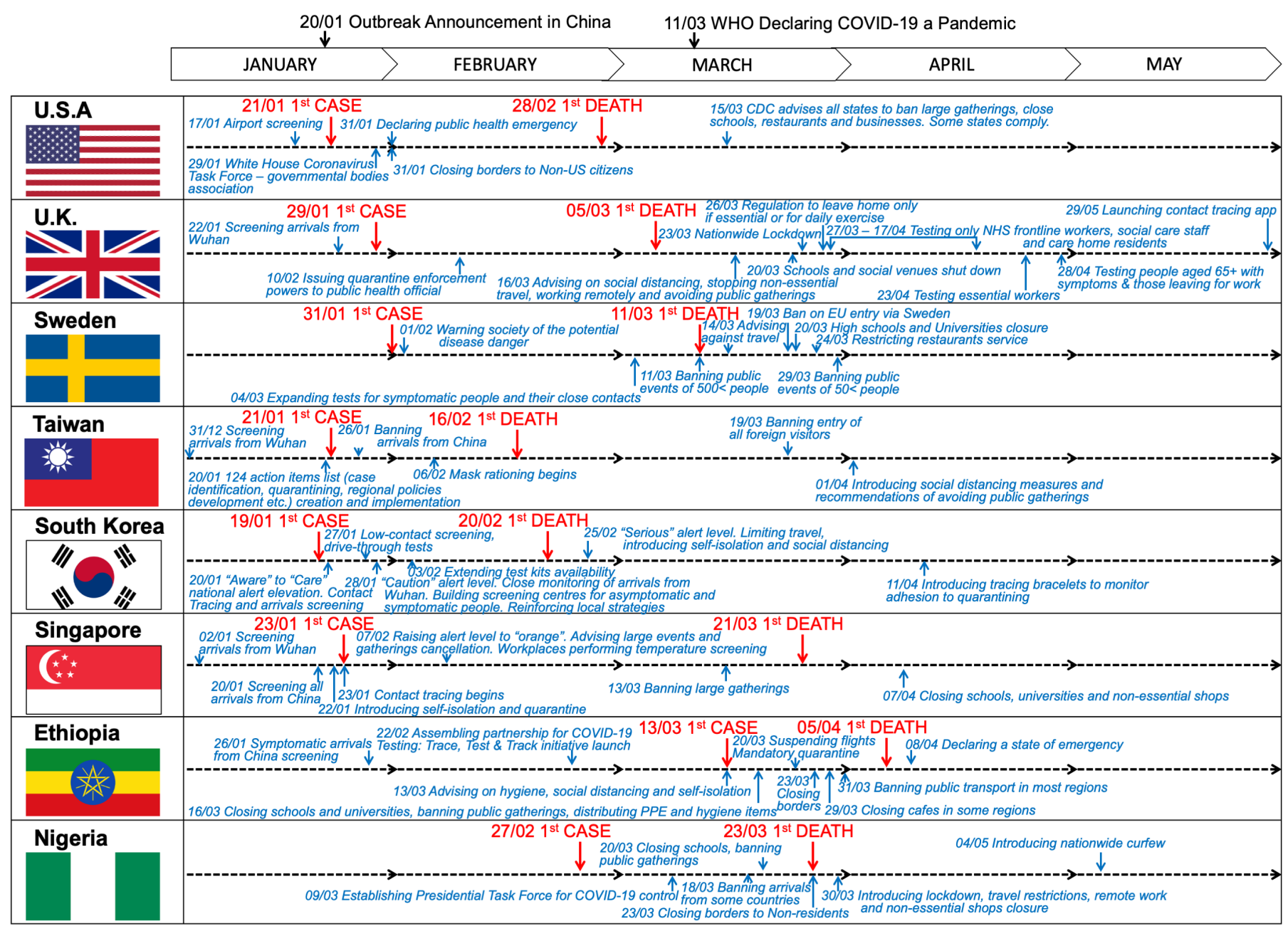

Figure 1 Timeline of COVID-19 control strategies implementation in the period from January to May 2020.

rate constant, doubling time and goodness of fit $\mathrm{R}^{2}$ were quantified.

Hofstede's cultural dimensions were analysed to estimate the influence of cultural values on decision making and adherence to measures (figure 4$).{ }^{40}$ Values ranging from 0 to 100 aim to to measure the influence of society's culture in different countries on six values: Power Distance Index (PDI): to which degree less powerful members of a society accept and expect the power to be distributed unequally; Individualism Versus Collectivism (IDV): to which degree members of a society selfimage themselves as 'I' than 'we' and expect to take care of themselves rather than relying on others in selfless exchange; Masculinity Versus Femininity (MAS): degree of preference in a society for achievement, heroism, assertiveness and material rewards for success other than of cooperation, modesty, caring for weak and quality of life; Uncertainty Avoidance Index (UAI): degree of reliance on codes and guidelines, and intolerance of uncertainty and ambiguity in opposite to the relaxed attitude where practice counts more than principles; Long-Versus ShortTerm Orientation (LTO): degree of pragmatic approach, prioritising preparations for future rather than viewing societal change with suspicion; and Indulgence Versus
Restraint (IVR): degree of allowing free human drives related to enjoying life rather than regulating needs by strict social norms.

The availability of hospital and ICU beds, life support equipment, medical staff and a country's spend on healthcare was analysed using publicly available information (figure 5A,B) ${ }^{39}{ }^{41-57} \mathrm{~A}$ cumulative stacked graph was constructed to show healthcare resource proportion in each country compared with the total amount across all eight countries. Table of the healthcare resources including hospital and ICU beds, ventilators and physicians values were estimated per 1000 people of population in each country.

\section{Patient and public involvement}

Patients and/or the public were not involved in the design, or conduct, or reporting, or dissemination plans of this research.

\section{DISCUSSION}

Analysis of governmental responses

Timeline of COVID-19 control strategies was build for visualisation of strategic interventions put in place as 


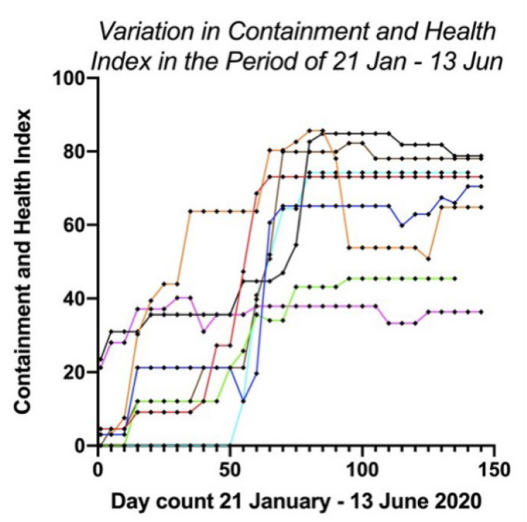

B

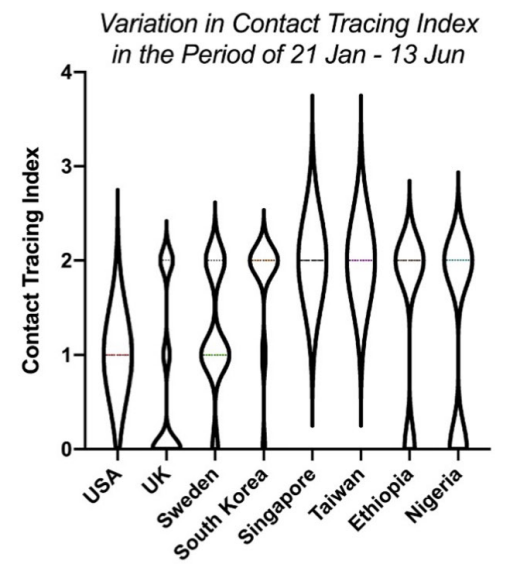

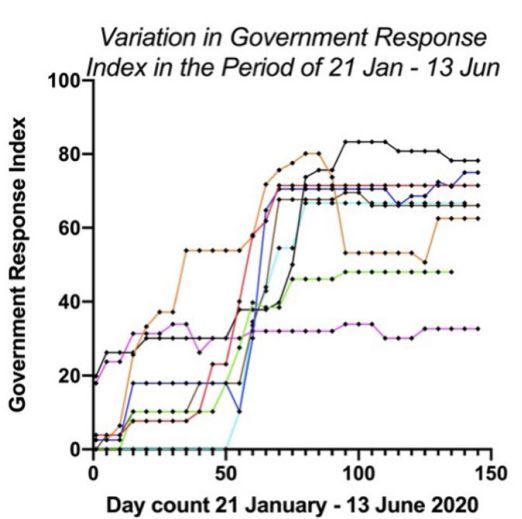

Variation in Information Campaigning Index

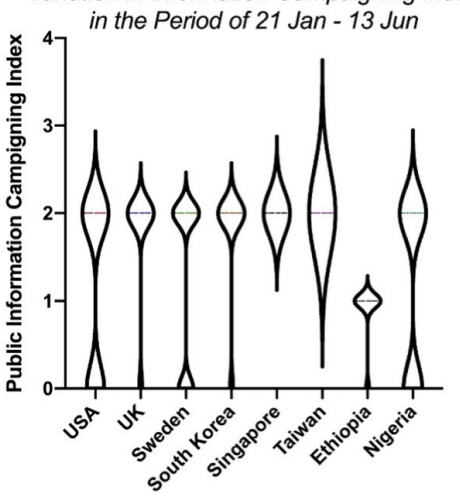

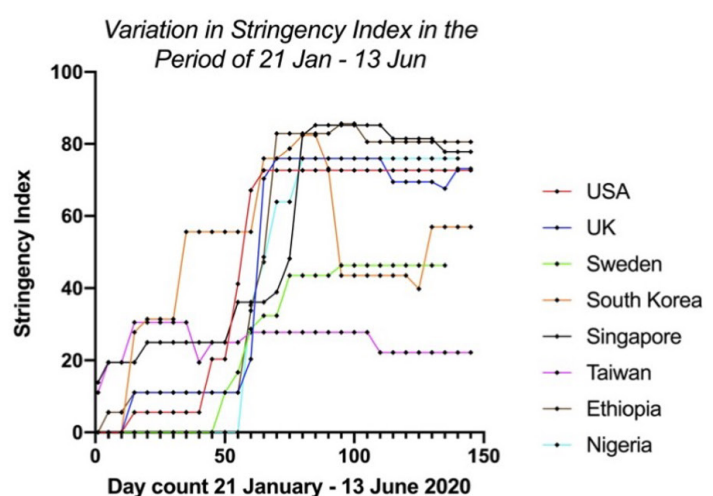

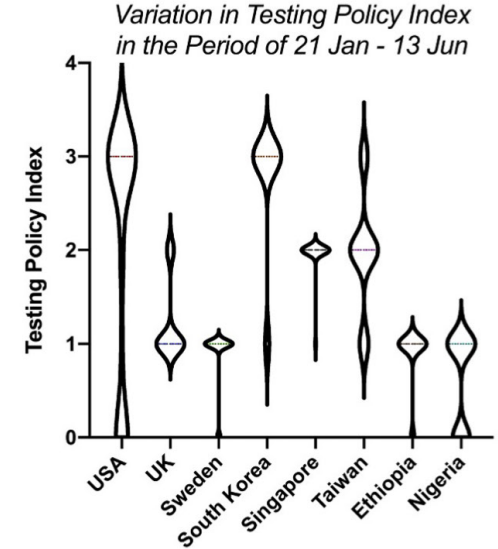

Figure 2 (A) Graphs of the changes in OxCGRT indices representing variations in government responses to COVID-19 in the selected countries in the period from 21 January to 13 June 2020. (B) Violin plot graphs of the variations in COVID-19 strategies in the selected countries in the period from 21 January to 13 June 2020.

a response of every chosen country to first COVID-19 infection case, first death caused by the virus and the COVID-19 outbreak announcement in China on the 20 January 2020, where the human-to-human transmission was confirmed (figure 1). Based on the dates of responses, Taiwan and Singapore reacted in advance of the outbreak announcement and first deaths in the countries. South Korea reacted on the day of the outbreak announcement with the national alert and contact tracing. USA, Taiwan and Singapore were also ahead of other countries with airport screening to tackle modes of international spread, with the USA being the first country to close its borders. The UK and Sweden had the slowest responses across developed countries that could have lead to the widespread community transmission occurring before government strategies were implemented. African countries generally reacted following the first reported case rather than implementing strategies shortly after the outbreak announcement. This might be a reflection of the lack of healthcare resources. At the beginning of the pandemic, there was a lack of comprehensive resources outlining the strategies put in place to tackle COVID-19.
For this reason, figure 1 was constructed from a number of local, country specific and news articles, which relies on the accuracy of the information in non-peer reviewed resources.

The variation in strategies and their speed of implementation is represented in figure $2 \mathrm{~A}, \mathrm{~B}$, analysed as of 24 June 2020. From the portfolio of all OxCGRT indices, those related to early governmental strategic actions were chosen. Since all three 'containment and health', 'government response' and 'stringency' indices are aggregates from the same response indicators considered in OxCGRT, variation patterns are virtually identical for all of them. The data suggest that within 25 days of the outbreak being announced, Singapore, South Korea and Taiwan had the strictest and fastest responses, followed by Ethiopia, USA and UK, while Nigeria responded only after 50 days of the outbreak announcement. The speed of the response is associated with the occurrence of the first COVID-19 case. Sweden is the only country whose indices differ at that stage-the Stringency Index started increasing only on the 45 th day-a result that is expected for a 'herd immunity' strategy. Countries with 
A

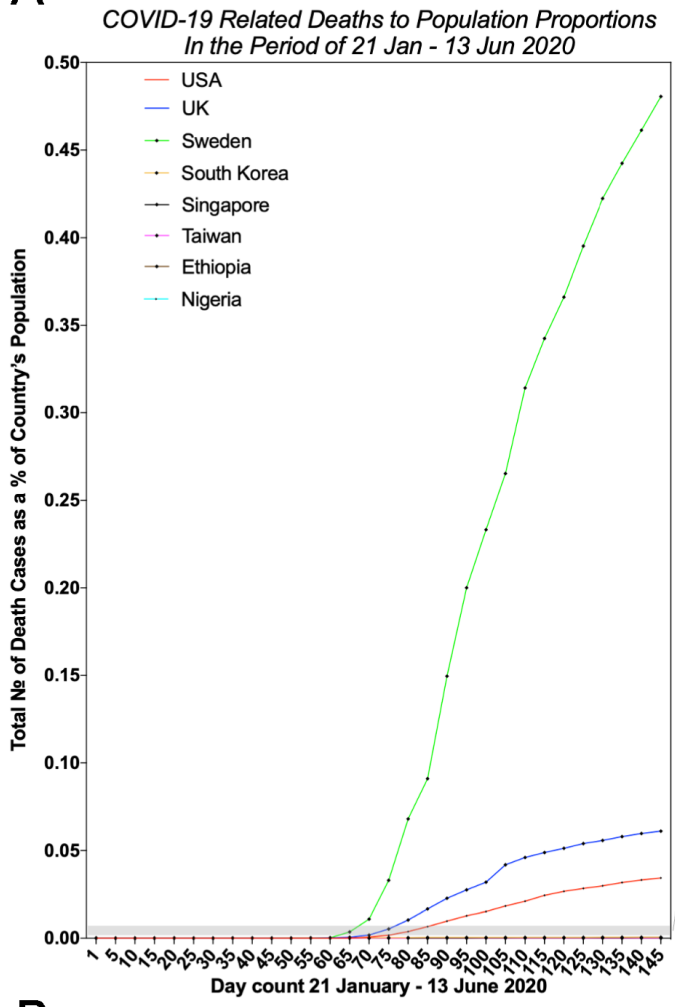

COVID-19 Related Deaths to Population Proportions In the Period of 21 Jan - 13 Jun 2020 (Magnified)

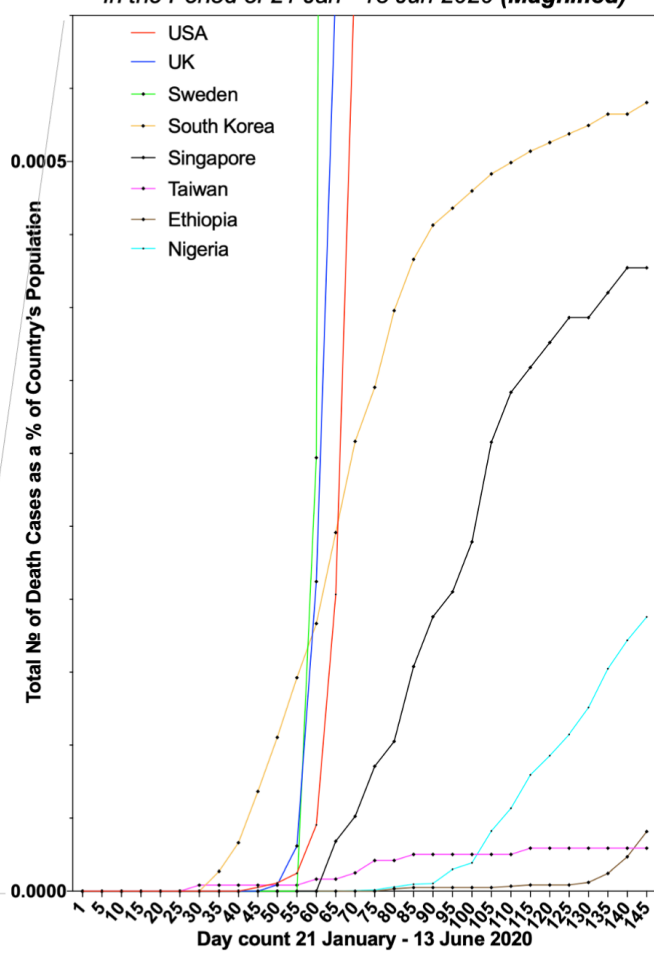

B

POPULATION PROPORTION ESTIMATES 50 DAYS AFTER THE FIRST COVID-19 DEATH CASE APPEARANCE

\begin{tabular}{|l|c|c|c|c|c|c|c|c|}
\hline COUNTRY & USA & UK & Sweden & South Korea & Singapore & Taiwan & Ethiopia & Nigeria \\
\hline $\begin{array}{l}\text { PROPORTION } \\
\text { ESTIMATES }\end{array}$ & 0.0128 & 0.0319 & 0.3144 & 0.0004 & 0.0004 & 0 & 0 & 0.0001 \\
\hline
\end{tabular}

C

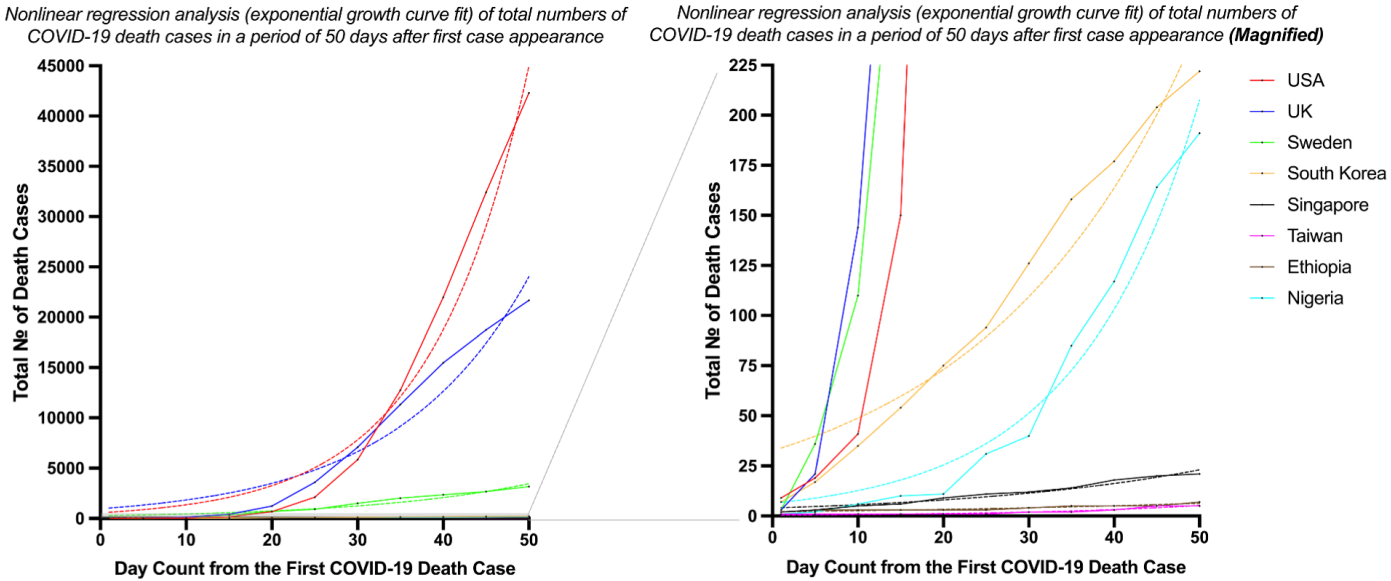

\begin{tabular}{|l|c|c|c|c|c|c|c|c|}
\hline COUNTRY & USA & UK & Sweden & South Korea & Singapore & Taiwan & Ethiopia & Nigeria \\
\hline $\begin{array}{l}\text { RATE } \\
\text { CONSTANT ( } \boldsymbol{k} \text { ) }\end{array}$ & 0.08742 & 0.06423 & 0.05109 & 0.04035 & 0.03516 & 0.04956 & 0.02198 & 0.06987 \\
\hline $\begin{array}{l}\text { DOUBLING } \\
\text { TIME (DAYS) }\end{array}$ & 7.93 & 10.79 & 13.57 & 17.18 & 19.72 & 13.99 & 31.54 & 9.92 \\
\hline R2 & 0.9755 & 0.9455 & 0.9428 & 0.9466 & 0.9561 & 0.9185 & 0.8950 & 0.9690 \\
\hline
\end{tabular}

Figure 3 (A) Graph showing the COVID-19 related deaths to population proportions in the selected countries in the period from 21 January to 13 June 2020. (B) Table of COVID-19 related deaths to population proportions in the selected countries 50 days after the first COVID-19 death case appearances. (C) Table and best-fit curve graphs of the nonlinear regression statistical test results estimating the degree of exponential growth in total numbers of COVID-19 death cases in a period of 50 days after first case appearance. 
Hofstede's Cultural Dimensions Comparison

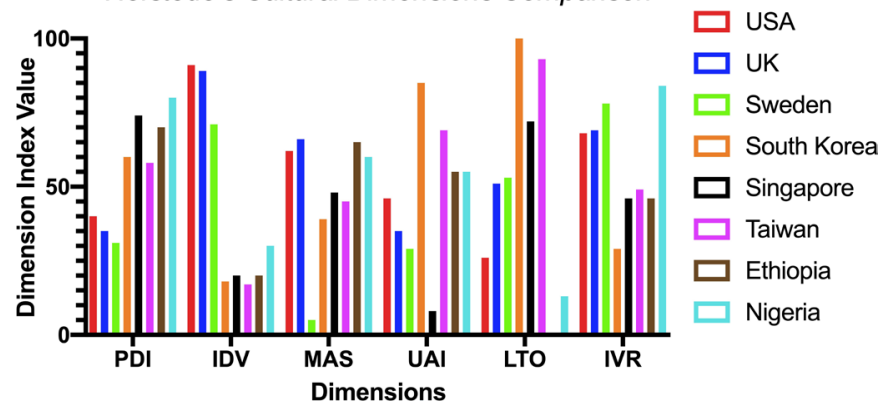

Figure 4 Graph of the Hofstede's cultural dimensions in the selected countries.

high indices, at the day of pandemic announcement, for example, Taiwan and South Korea, had lower indices 3-4 months into the pandemic suggesting that less stricter strategies with higher testing availability could be enough to contain the spread, while countries with zero or low OxCGRT indices had a rapid increase to high levels of indices 1-2 months into the pandemic. 'Contact tracing', 'information campaigning' and 'testing policies' were three indices that were hypothesised to represent the

A

Healthcare resources availability as a
share of total amount in the countries

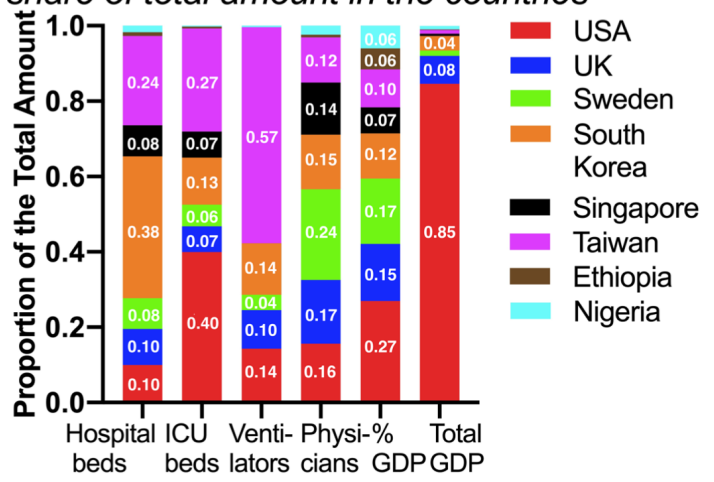

B

\begin{tabular}{|l|c|c|c|c|c|c|c|c|}
\hline COUNTRY & USA & UK & Sweden & $\begin{array}{c}\text { South } \\
\text { Korea }\end{array}$ & Singapore & Taiwan & Ethiopia & Nigeria \\
\hline $\begin{array}{l}\text { HOSPITAL } \\
\text { BEDS }\end{array}$ & 2.9 & 2.8 & 2.4 & 11.0 & 2.4 & 6.9 & 0.3 & 0.5 \\
\hline ICU BEDS & 0.3500 & $\begin{array}{c}0.060 \\
*(0.15 \\
0)\end{array}$ & $\begin{array}{c}0.050 \\
(0.120)\end{array}$ & 0.110 & 0.060 & 0.240 & 0.004 & 0.002 \\
\hline $\begin{array}{l}\text { VENTILATOR } \\
\text { S }\end{array}$ & $\begin{array}{c}0.210 \\
*(0.604)\end{array}$ & 0.150 & 0.060 & 0.200 & $* *$ & 0.840 & 0.001 & 0.005 \\
\hline PHYSICIANS & 2.6 & 2.8 & 4.0 & 2.4 & 2.3 & 2.0 & 0.1 & 0.4 \\
\hline $\begin{array}{l}\text { \% GDP } \\
\text { SPENT ON } \\
\text { HEALTHCARE }\end{array}$ & 17.1 & 9.6 & 11.0 & 7.6 & 4.4 & 6.4 & 3.5 & 3.8 \\
\hline $\begin{array}{l}\text { CHE } \\
\text { (\$ BILLION) }\end{array}$ & 3332.0 & 291.56 & 57.97 & 150.87 & 23.21 & 37.50 & 7.53 & 37.65 \\
\hline
\end{tabular}

Figure 5 (A) Cumulative stacked graph of healthcare resources availability as a share of total amount. (B) Table of the healthcare resources available in the selected countries. *Increased number in temporary ICU units/ventilator supplies as a result of COVID-19 pandemic. ${ }^{* *}$ Information is not available; however, Singaporean Ministry of Health have issued a statement on 4 May 2020 'We have also ensured a sufficient supply of ventilators and other ICU accessories....' ICU, intensive care unit. most effective strategies. From the median values of indices and plot densities, it can be inferred that Taiwan had the most coordinated information campaigning; strict contact tracing measures were applied the longest in Singapore and Taiwan followed by Nigeria, Ethiopia and South Korea, while UK, USA and Sweden had minimal or no contact tracing; testing measures were strongest in the USA and South Korea, followed by Taiwan and Singapore. Even though OxCGRT is a beneficial index for the purpose of analysis, there are numerous factors that might have been overlooked in this analysis. OxCGRT was available early in the pandemic and covered multiple factors. Quantifying the spectrum of responses into a numerical scale required subjective decision making, especially where a narrow range was used. Indices were also limited to the availability of data on governmental responses, which was scarce at the beginning of the pandemic.

The mathematical modelling undertaken demonstrates that a combination of self-isolation, household quarantine and manual contact tracing of all contacts was found to be most effective, reducing transmission by $64 \%$, while random mass testing had only a $5 \%$ reduction effect. ${ }^{58}$ Rapid identification and isolation of cases, quarantining of some contacts and monitoring of others was proven to be effective in supressing expansion of the outbreak. ${ }^{59}$ Some research points to contact tracing and case isolation being sufficient to control a COVID-19 outbreak. ${ }^{60}$ However, since the feasibility of this method decreases with a delay between first symptom occurrence and isolation, it has to be implemented as fast as possible. Weekly screening of healthcare workers and at-risk groups reduced the COVID-19 transmission by $25 \%-33 \%$, while widespread testing of the general population was stated to unlikely have a better effect on the transmission than contact tracing and isolation. ${ }^{61}$ The data from South Korea, however, potentially disputes this, as their early implementation of widespread screening significantly lowered the COVID-19 cases, without need of going into a lockdown. ${ }^{62}$ It can be argued that widespread testing coupled with contact tracing and isolation would be effective in capturing both asymptomatic and symptomatic cases. A significant concern is the willingness to engage with track and trace programmes and adherence to isolation if identified as at risk. This may point to the impact of cultural norms, as Asian countries were more accepting, while in Western countries, people viewed it as personal choice. For example, in December 2020, many months after the launch, only one-third of residents in England and Wales had installed the phone app enabling contact tracing. ${ }^{63}$

Early in the pandemic, it was not clear whether social distancing and lockdown on their own could reduce transmission and delay spread. ${ }^{64}$ However, the impact of lockdown on transmission in Europe was found to be significant, with $81 \%$ reduction rates on average. ${ }^{65}$ Chinese models have shown that, if implemented early enough, that is, as of 1 January 2020, it could have significantly limited the epidemic, reducing infections by up to 
$98.9 \% .^{66}$ It was projected that the immediate introduction of different extreme physical distancing measures could push the transmission to households, resulting in a shorter epidemic and a lowered and flattened peak of COVID-19 daily cases. ${ }^{67}$ Later studies concluded that earlier implementation of lockdown is a better option for reducing COVID-19 spread rather than delayed lockdown after introducing other physical distancing interventions. ${ }^{68}$ Since almost every country's response was too slow for this to be achieved, social distancing and lockdown methods were implemented more as a delay than contain' strategy. Several modelling studies have shown that early implementation of border closures would have limited viral transmission in the early phase of the pandemic; however, for countries that act as global transport hubs, this is more challenging. ${ }^{69}$ Based on the US early borders closure, and the outcome of their COVID-19 spread, this strategy cannot be effective on its own. While it is important to promote transparency and follow the guidance of international authorities, in critical situations, an immediate response might be necessary. Having extreme measures implemented rapidly for a short period of time is arguably a more effective option long term than delaying and softening the restrictions.

\section{Analysis of deaths associated with COVID-19}

Based on publicly available data, as of 13 June 2020, deaths per capita were highest for the UK (611.04) followed by Sweden (480.54) and the USA (343.74). Deaths per capita in South Korea (5.4), Singapore (4.27), Taiwan (0.29), Ethiopia (0.0034) and Nigeria (1.88) were very low. Although difficult to quantify, it is essential to acknowledge also the indirect impact of COVID-19 on death rates, for example, an increase in the rate of suicides. Additionally, data show that people with potentially lifethreatening conditions, such as strokes and heart attacks, were less likely to seek urgent hospital care. ${ }^{138}{ }^{39}$ In the UK, there was a $48 \%$ fall in major Emergency department (A\&E) visits and a 50\% decrease of heart attack admissions in the first half of $2020 .^{7071}$ In some countries, the reported number of stroke admissions decreased by $50 \%-80 \%{ }^{72}$ Changes to cancer treatment regimes and suspension of clinical trials could have also contributed to death rates.

Country demographics have a significant impact on mortality rates with the number of intensive care unit (ICU) admissions highest in those aged 65 years and above. The percentage of $65+$ years old people as a proportion of the population in the selected countries is: USA: $16.2 \%$, UK: $18.7 \%$, Sweden: $20.1 \%$, Taiwan: $15.1 \%$, South Korea: $15.1 \%$, Singapore: $12.3 \%$, Ethiopia: $3.5 \%$ and Nigeria: $2.7 \% .{ }^{734}$ Given these statistics, it is probable that those countries with predominantly younger populations will have fared better. Death rates are also affected by variation in data collection and should be considered with caution. ${ }^{75}$ It is acknowledged that this approach relies on countries providing accurate information on numbers of deaths, something that is not possible to determine. It is difficult to account for comorbidities, but the WHO encouraged accurate estimates by normalising a definition of COVID-19 death based on the probable or confirmed COVID-19 infection, unless there was a clear alternative cause of death.

Given higher mortality in the elderly, age-specific mortality would be a more appropriate metric, with age standardised infected population rates being a useful alternative. However, at the beginning of pandemic, there was no detailed data on statistics within different age populations.

This analysis used mortality rates as a metric of effectiveness to governmental response due to the relatively straightforward comparability of values. The numbers of deaths attributable to COVID-19 were chosen because measuring the number of reported cases may not be accurate due to the presence of asymptomatic patients, levels of testing of the general population and a lack of accurate or available diagnostics. Numbers of COVID-19 cases or COVID-19 hospital admissions could also have been used a a benchmark of effectiveness; however, it can be argued that the lack of testing would not have provided an accurate picture of the spread of the pandemic and therefore the effectiveness of any measures implemented. For example, in the USA, a country with the highest number of cases and good availability of tests, the COVID-19 infections count was estimated to be 3-20 times higher than the numbers of confirmed cases ${ }^{76}$ Population groups tested, selection criteria and COVID-19 case definition also varied between different countries at the beginning of the pandemic.

COVID-19 deaths to population proportions were the highest for Sweden, UK and USA (figure 3A,B and C). There was a steep acceleration in numbers of deaths in every country apart from Taiwan. Further statistical analysis was performed to quantify the degree of the exponential growth of COVID-19 cases in the selected countries.

Those countries with most effective strategies would presumably have lower goodness of fit to the exponential growth equation (measured in $\mathrm{R}^{2}$ ), smaller growth rate constant (measured in $k$ ) and longer time it took for cases to double (measured in doubling-time).

The smallest rate constants and the largest doublingtime values were in Ethiopia, Singapore and South Korea. Considering the estimates, all countries apart from Ethiopia and Taiwan had exponential growth in COVID-19 death cases.

It is likely that Ethiopia and Nigeria results are significantly downplayed owing to the lack of postmortem diagnostic facilities.

The importance of the individual characteristics of countries should not be underestimated. It is likely that countries such as the USA, which act as a 'travel hub', had widespread community transmission prior to index cases having been identified, hence challenging and limiting contract tracing and isolation efforts. 


\section{Cultural aspect in the effectiveness of governmental} strategies

Hofstede's cultural dimensions were analysed to estimate the influence of cultural values on the perception of governmental strategies, decision making and adherence to regulations (figure 4). ${ }^{40}$ Three out of six values were likely have the strongest impact IDV, LTO and IVR. The USA, UK and Sweden, countries with individualistic norms, fared much worse than collectivism-oriented countries like Singapore, Taiwan or South Korea. Concurrently, the three selected Asian countries are also the most long-term oriented ones and have the highest restraint indications explaining their preparedness and compliance to regulations imposed during the COVID-19 pandemic. High collectivism values might have had a role to play in Nigeria and Ethiopia too. It is acknowledged that it is difficult to measure a complex concept such as culture, comprehensively. Hofstede uses only six dimensions to quantify cultural characteristics of citizens within countries. The data are limited to the set of questions asked in surveys and could thus exclude factors such as migration, diversity and residents living in difficult to reach geographical locations.

Cultural norms of collectivism and obedience to restraints in Asia lead to the acceptance of country-wide shutdowns and contact tracing, whereas the UK, USA and Sweden were more concerned about their citizens privacy rights and often value their liberty more than the societal need of, for example, lockdown. As a result of high levels of environmental pollution, and previous disease outbreaks like SARS, Asian people are more used to wearing masks in everyday life, whereas in other countries, it could be judged and criticised as less acceptable. In Asia or Africa, it could be enough to inform the public of the necessary measures, while in UK or USA, the governments need to appeal to their citizens in other ways, such as via adverts and media. It can be argued that Asian countries might have been better prepared, given their experience of dealing with the SARS and MERS pandemics. Having dealt previously with disease outbreaks, governments are probably more willing to implement stricter measures such as travel restrictions and full lockdown.

There are many other confounders and risk factors, such as obesity and the prevalence of chronic diseases, now known to have a significant impact on death rates; however, these factors were not clearly associated with COVID-19 related deaths at the beginning of pandemic. Apart from cultural impact, there could also be other factors, for example, clear and consistent guidance early on in the pandemic that influenced adherence and hence reduced the number of deaths. The impact of political environments and attempts to minimise economic disruption is acknowledged as a factor that may impact on the effectiveness of any strategy; however, analysis of such data is beyond the scope of this research. In the early phases of the pandemic, death rates were assumed to be the key metric of effectiveness measurement; however, governments could have prioritised minimisation of impact on health services or economic disruption instead, hence influencing their approach to strategy design and implementation.

Healthcare resources availability: implications for the impact of COVID-19 on individual countries

Estimates of healthcare resources were considerably lower for Ethiopia and Nigeria, apart from the absolute value spent on healthcare from GDP in Nigeria, which could perhaps be attributed to the country having the seventh's highest population in the world (figure 5). ${ }^{39} 41-57$ In South Korea, Singapore and Taiwan, numbers of ICU beds and ventilators were sufficient to deal with the incoming patients with COVID-19. Estimates for the USA are particularly noteworthy as the number of deaths are very high considering both the healthcare budget and the numbers of ICU beds and ventilators available. Based on the estimates for Sweden and UK, it is most likely that both countries were struggling with high numbers of patients with COVID-19, and this could have contributed to higher death rates in both countries. Healthcare resource analysis was heavily impacted by the lack of data availability at the beginning of the pandemic and is limited to the accuracy of information shared. In particular, the number of hospital beds, ventilators and physicians was obtained from non-peer-reviewed journals, and it is acknowledged that countries may have inflated these figures to improve their global image.

Even the best all-encompassing strategies might not be suitable for every country. Singapore, USA, Taiwan, Sweden, UK and South Korea have GDP based on Purchasing Power Parity (PPP) per capita ranging from $\$ 44700$ to $\$ 103200$, while in Nigeria, it is $\$ 6000$ and Ethiopia $\$ 2500 .^{77}$ Despite countries with low GDPs that are highly vulnerable to economic stress, with many lives dependent on having to go to work, many still imposed costly lockdowns. ${ }^{78}$ These countries faced additional challenges; with the economies of other countries also struggling, the funding of welfare and health programmes were cut.

GDP, provision of healthcare resources and cultural norms influence the death rates in every country. While deaths in the USA, UK, Sweden, South Korea, Taiwan, Ethiopia and Nigeria could largely be attributed to the rates of transmission and demographics in a country, numbers in Singapore require a different explanation: $80 \%$ of the cases there originated from foreign workers' dormitories, with community cases accounting for just $10 \% .{ }^{79}$ All diagnosed patients there were kept in isolation facilities with available medical care if required. ${ }^{80}$ At the beginning of the pandemic, there were more than 18000 -bed spaces. Due to the younger age of the workers and the mild nature of the symptoms, the majority of them did not require hospitalisation, thereby preventing the healthcare system from being overwhelmed. ${ }^{81}$ In Europe, half of 
the COVID-19 fatalities occurred in nursing homes; in Singapore, a limited number of nursing homes had cases. As a result of the SARS epidemic in 2003, Singapore and many other Asian countries improved their preparedness and capacity for future outbreaks. Hospital facilities, availability of ICU beds, ventilators medical staff and PPE influenced government strategies to prevent healthcare systems from becoming overwhelmed. PPE numbers of, for example, face masks or gloves were not analysed due to difficulties in finding comprehensive data, the variability of standards across countries and debates about their effectiveness early on in the pandemic. In addition, there was lack of N95 and other high filter efficient respirators availability to general populations, with prioritisation to medical professionals and infected patients. Early in the pandemic, medical masks filter efficiency was shown to be $2 \%-38 \% .{ }^{82}$ As the pandemic progressed, evidence of the effectiveness of medical masks in reducing COVID-19 transmisibility was demonstrated, however still not beyond a 'low to moderate' level. Countries with low GDP do not have the same level of technologies and healthcare capacities, and access to treatment for rural communities is particularly challenging. In spring 2020, it was estimated that at least 121000 critical care beds were needed for the whole of Africa, while only 9800 ICU beds were available. ${ }^{83}$ In support of the analysis performed, it was shown that increased mortality rates, lack of hospital beds and ICU bed capacity is strongly correlated with a country's income status. ${ }^{84}$ A large UK study showed that one-third of patients admitted to hospital with COVID-19 died.$^{85}$ In both studies, the vast majority of deaths were due to comorbidities, with cardiac disease $29 \%$, diabetes $19 \%$, chronic pulmonary disease $19 \%$ and asthma $14 \%$ prevalence in the UK. In addition to these comorbidities, diseases like HIV, tuberculosis and malnutrition are common in low-income countries. The household setting-key for COVID-19 transmission-is different in lower income countries with a substantially higher proportion of multigenerational households having contact with a wide range of age groups.

Geographical factors such as climate and population density, ethnicity and demographic data are factors that were not heavily considered in the analysis as no conclusive data on their impact on COVID-19 related deaths was available early on in the pandemic. It is likely that COVID-19 spread is higher in countries with larger number of highly populated areas and higher population density. However, in 2020, out of the selected countries Singapore, Taiwan and South Korea had 8358, 672.6 and 527.3 people per square metre, respectively, while for the USA and Sweden, the numbers were 36.19 and 24.61 , respectively. ${ }^{86}$ This suggests that highly populated countries do not necessarily have higher COVID-19 spread, highlighting that strict adhesion to constraint measures with quick identification of infected cases should significantly limit the impact of the spread. Furthermore, it suggests that countries with smaller territories may have advantage as a result of more manageable geographies.

\section{CONCLUSION}

The COVID-19 pandemic has had a significant impact on most countries. This analysis aimed to identify strategies that, if implemented at the start of a pandemic, could quickly contain the threat and minimise the associated effects on healthcare resources and lives. The main conclusion from this analysis is that the speed at which strategies were implemented played the most significant role in reducing the number of COVID-19 cases, and possibly, death rates early on in the pandemic. Selection of the measures implemented is also critical, with widespread screening and containment strategies, like contact tracing, being perhaps the most successful options. It is hard to speculate which methods on their own are the most crucial or successful ones in preventing and controlling the COVID-19 pandemic. Perhaps as a result of past epidemics such as MERS and SARS, Asian countries were better prepared and more willing to implement and adhere to strict measures.

The difference in measures selected, and their implementation, was likely dependent on factors like demographics, population size and the availability of healthcare resources. However, it is not necessarily total GDP spent on healthcare, but the right allocation and combination of facilities available that matters. The number of cases and deaths may be influenced by cultural trait disparities, with lower numbers in societies whose members prioritise their nations collective well-being over the individual to differing degrees, accepting privacy intrusion where necessary, strictly obeying recommendations and adhering to measures. According to the analysis of the available data, Taiwan, South Korea, Singapore and, perhaps, Ethiopia dealt with the outbreak in the most effective manner. So many biases and confounders may put the proposed inferences in doubt, but only collective evidence with time will allow for definitive conclusions.

Despite evidence showing a clear lack of preparedness in many countries, it is hard to speculate whether the COVID-19 pandemic could have been prevented. With questionable reliability of the declared numbers of cases, delay in WHO guidance and a lack of transparency, perhaps the stricter measures like immediate shutting of borders or isolation in specialised facilities would have effectively curtailed the spread. Improved transparency and information sharing between governments with respect to disease outbreaks will enable the WHO to publicise more timely accurate information and policies to prevent rapid spread and potentially avert future global pandemics. Strict early shielding of elderly and vulnerable populations would probably have decreased COVID-19 deaths substantially, as 
it did in Singapore. Widespread access to testing and effective track and trace systems early in the pandemic can significantly limit spread. Cultural norms impact on implementation and adherence to policies should not be ignored when considering global strategies. Containing the pandemic and eradicating COVID-19, or any future pandemic the world may face, requires global cooperation and transparency.

While difficult to achieve in low-income countries, governments should have in place up-to-date policies that enable the rapid scaling of healthcare resources, including manufacturing facilites.

Pandemic preparedness needs to be viewed globally, while lessons have undoubtably been learnt, considerably more effort needs to be invested in surveillance and preparedness plans in order to prevent a reoccurrence of the tragedies of the COVID-19 pandemic. Having up-to-date preprepared pandemic strategies will enhance the response of individual countries, and global preparation, for any future viral outbreaks.

Contributors AN is the author responsible for the overall content of the paper as the guarantor. AN and JV contributed to the proposal of conceptual ideas, design and planning. AN conducted the research, interpreted the results and analysed the data. AN wrote the manuscript with verification and writing contributions of JV. Both AN and JV contributed to the final version. JV supervised the project. AN had access to the data, accepts full responsibility for the work and the conduct of the study. AN controlled the decision to publish. The corresponding author attests that all listed authors meet authorship criteria and that no others meeting the criteria have been omitted.

Funding The authors have not declared a specific grant for this research from any funding agency in the public, commercial or not-for-profit sectors.

Competing interests None declared.

Patient consent for publication Not applicable.

Ethics approval This study does not involve human participants.

Provenance and peer review Not commissioned; externally peer reviewed.

Data availability statement Data sharing not applicable as no datasets generated and/or analysed for this study. No additional data available. Publicly available thirdparty data were used for the research and data analyses.

Open access This is an open access article distributed in accordance with the Creative Commons Attribution Non Commercial (CC BY-NC 4.0) license, which permits others to distribute, remix, adapt, build upon this work non-commercially, and license their derivative works on different terms, provided the original work is properly cited, appropriate credit is given, any changes made indicated, and the use is non-commercial. See: http://creativecommons.org/licenses/by-nc/4.0/.

ORCID iD

Alexandra Nikolaeva http://orcid.org/0000-0001-9876-8250

\section{REFERENCES}

1 World Health Organisation. Coronavirus diseases (COVID-19) situation reports. Available: https://www.who.int/emergencies/ diseases/novel-coronavirus-2019/situation-reports [Accessed 25 May 2020].

2 Worldometer. Countries where COVID-19 has spread, 2020. Available: https://www.worldometers.info/coronavirus/countrieswhere-coronavirus-has-spread/ [Accessed 24 May 2020].

3 Velavan TP, Meyer CG. The COVID-19 epidemic. Trop Med Int Health 2020;25:278-80.

4 CDC. 10 years of international health regulations: why they matter, 2015. Available: https://www.cdc.gov/globalhealth/stories/ten_years_ ihr.htm [Accessed 27 May 2020].

5 WHO. IHR state party self-assessment annual report (SPAR), 2021. Available: https://extranet.who.int/sph/spar [Accessed 3 Aug 2021].
6 Cunningham PW. The health 2020: texts to federal government mental health hotline up roughly 1,000 percent, 2020. Available: https://www.washingtonpost.com/news/powerpost/paloma/thehealth-202/2020/05/04/the-health-202-texts-to-federal-governmentmental-health-hotline-up-roughly-1-000-percent/5eaae16c602ff15f b0021568/?itid=ap_paigewinfield\%20cunningham\&itid=lk_inline_ manual 12 [Accessed 15 Jun 2020].

7 Yeager A. Predicting future zoonotic disease outbreaks, 2018. Available: https://www.the-scientist.com/features/predictingfuture-zoonotic-disease-outbreaks-64257 [Accessed 27 May 2020].

8 Kraemer MUG, Cummings DAT, Funk S, et al. Reconstruction and prediction of viral disease epidemics. Epidemiol Infect 2018;147:e34:1-7.

9 Smith DJ, Lapedes AS, de Jong JC, et al. Mapping the antigenic and genetic evolution of influenza virus. Science 2004;305:371-6.

10 Watts J. Delay is deadly: what Covid-19 tells us about tackling the climate crisis, 2020. Available: https://www.theguardian.com/ commentisfree/2020/mar/24/covid-19-climate-crisis-governmentscoronavirus [Accessed 15 Jun 2020].

11 Milne R. Sweden bucks global trend with experimental virus strategy, 2020. Available: https://www.ft.com/content/31de03b8-6dbc-11ea89df-41bea055720b [Accessed 17 Jun 2020].

12 Winberg M. Därför kan Sverige inte utfärda utegångsförbud, 2020. Available: https://www.svt.se/nyheter/vetenskap/darfor-kan-sverigeinte-utfarda-utegangsforbud [Accessed 19 Jun 2020].

13 Reuters. Fact check: Sweden has not achieved herd immunity, is not proof that lockdowns are useless, 2020. Available: https://www. reuters.com/article/uk-factcheck-prageru-sweden-herd-immunitidUSKBN28C2R7 [Accessed 3 Mar 2021].

14 HealthManagement.org. Where are the most effective anti-COVID-19 strategies, 2020. Available: https://healthmanagement.org/c/ hospital/news/where-are-the-most-effective-anti-covid-19-strategies [Accessed 17 Jun 2020].

15 Pqubay A. Ethiopia's unconventional COVID-19 response, 2020. Available: https://www.weforum.org/agenda/2020/06/ethiopiacovid19-response/ [Accessed 18 Jun 2020].

16 LSHTM (London School of Hygiene \& Tropical Medicine). Strategies combining self-isolation, moderate physical distancing and shielding likely most effective COVID-19 response for African countries, 2020. Available: https://www.lshtm.ac.uk/newsevents/news/2020/ strategies-combining-self-isolation-moderate-physical-distancingand-shielding [Accessed 19 Jun 2020].

17 CNBC Africa. Unpacking Nigeria's COVID-19 strategy, 2020. Available: https://www.cnbcafrica.com/videos/2020/06/05/ unpacking-nigerias-covid-19-strategy/ [Accessed 19 Jun 2020].

18 Kantis C, Kiernan S, Socrates Bardi J. Timeline of the coronavirus, 2020. Available: https://www.thinkglobalhealth.org/article/updatedtimeline-coronavirus [Accessed 18 Jun 2020].

19 Taiwan Today. CDC implements extra inspection measures for Wuhan fights, 2020. Available: https://taiwantoday.tw/news. php?unit=2,6,10, 15,18\&post=168773 [Accessed 18 Jun 2020].

20 Folkhälsomyndigheten. Nytt bekräftat fall av covid-19, 2020. Available: https://www.folkhalsomyndigheten.se/nyheter-och-press/ nyhetsarkiv/2020/februari/nytt-bekraftat-fall-av-covid-19/ [Accessed 18 Jun 2020]

21 Goodman R, Schulkin D. Timeline of the coronavirus pandemic and U.S. response, 2020. Available: https://www.justsecurity.org/69650/ timeline-of-the-coronavirus-pandemic-and-u-s-response/ [Accessed 18 Jun 2020]

22 Cooper M, Smith M, Landler M. C.D.C. gives new guidelines, New York to close restaurants and schools and Italian deaths rise, 2020. Available: https://www.nytimes.com/2020/03/15/world/coronaviruslive.html [Accessed 18 Jun 2020].

23 Soucheray S. Coroner: first US COVID-19 death occurred in early February, 2020. Available: https://www.cidrap.umn.edu/newsperspective/2020/04/coroner-first-us-covid-19-death-occurred-earlyfebruary [Accessed 18 Jun 2020].

24 Yong M. Timeline: how the COVID-19 outbreak has evolved in Singapore so far, 2020. Available: https://www.channelnewsasia. com/news/singapore/singapore-covid-19-outbreak-evolvedcoronavirus-deaths-timeline-12639444 [Accessed 18 Jun 2020].

25 Wang CJ, Ng CY, Brook RH. Response to COVID-19 in Taiwan: big data analytics, new technology, and proactive testing. JAMA 2020;323:1341-2.

26 Taiwan Centers for Disease Control. Press releases, 2020. Available: https://www.cdc.gov.tw/En/Bulletin/List/7tUXjTBf6paRvrhEl-mrPg [Accessed 18 Jun 2020].

27 Lee D, Lee J. Testing on the move: South Korea's rapid response to the COVID-19 pandemic. Transp Res Interdiscip Perspect 2020;5:100111. 
28 The Local SE. Coronavirus LATEST: what you need to know about the outbreak in Sweden, 2020. Available: https://www.thelocal.se/ 20200310/timeline-how-the-coronavirus-has-developed-in-sweden [Accessed 18 Jun 2020].

29 Beadsworth J, Walawalkar A. UK coronavirus timeline: from liberty to lockdown, 2020. Available: https://eachother.org.uk/uk-coronavirustimeline-from-liberty-to-lockdown/ [Accessed 18 Jun 2020].

30 Dunn P, Allen L, Cameron G, et al. A timeline of national policy and health system responses to COVID-19 in England, 2020. Available: https://www.health.org.uk/news-and-comment/charts-andinfographics/covid-19-policy-tracker [Accessed 18 Jun 2020].

31 WHO. First case of COVID-19 confirmed in Ethiopia, 2020. Available: https://www.afro.who.int/news/first-case-covid-19-confirmedethiopia [Accessed 19 Jun 2020].

32 Shaba ARA. Ethiopia coronavirus: key updates between March 16 - May 16, 2020. Available: https://www.africanews.com/2020/05/ 19/ethiopia-s-coronavirus-rules-crowd-ban-free-transport-regulateessentials-etc/ [Accessed 19 Jun 2020].

33 AFRICA CDC. AU and Africa CDC launch partnership to accelerate COVID-19 testing: trace, test and track, 2020. Available: https:// africacdc.org/news-item/african-union-and-africa-centres-fordisease-control-and-prevention-launch-partnership-to-acceleratecovid-19-testing-trace-test-and-track/ [Accessed 19 Jun 2020]

34 Tony Blair Institute For Global Change. Social distancing case studies: Rwanda, Vietnam, Ghana, Nigeria, Senegal and Kenya, 2020. Available: https://institute.global/sites/default/files/inlinefiles/Tony\%20Blair\%20Institute\%2C\%20Social\%20Distancing\% 20Case\%20Studies.pdf [Accessed 19 Jun 2020].

35 Shobiye H. Fintiri orders Adamawa lockdown over coronavirus, 2020 Available: https://www.vanguardngr.com/2020/03/fintiri-ordersadamawa-lockdown-over-coronavirus/ [Accessed 19 Jun 2020].

36 Abuja OA. Buhari declares nationwide curfew from Monday, 2020. Available: https://punchng.com/buhari-declares-nationwide-curfewfrom-monday/ [Accessed 19 Jun 2020].

37 Petherick A, Kira B, Angrist N. Variation in Government responses to COVID-19, 2020. Available: https://www.bsg.ox.ac.uk/research/ publications/variation-government-responses-covid-19 [Accessed 24 Jun 2020].

38 Thomala LL. COVID-19 confirmed case, death and recovery trend in Taiwan 2020, 2020. Available: https://www.statista.com/statistics/ 1108537/taiwan-novel-coronavirus-covid19-confirmed-deathrecovered-trend/ [Accessed 19 Jun 2020].

39 Worldometer. Current world population, 2020. Available: https://www. worldometers.info/world-population/ [Accessed 13 Jun 2020]

40 Hofstede Insights. National culture. Available: https://hi.hofstedeinsights.com/national-culture [Accessed 27 Jun 2020].

41 Blimark M, Örtenwall P, Lönroth H, et al. Swedish emergency hospita surgical surge capacity to mass casualty incidents. Scand J Trauma Resusc Emerg Med 2020;28:12.

42 Lai C-C, Ho C-H, Chang C-L, et al. Availability of critical care services in Taiwan under national health insurance. $\mathrm{Br} J$ Anaesth 2017;119:335-7.

43 Phua J, Faruq MO, Kulkarni AP, et al. Critical care bed capacity in Asian countries and regions. Crit Care Med 2020;48:654-62.

44 The World Bank. Hospital beds (per 1,000 people). Available: https:// data.worldbank.org/indicator/SH.MED.BEDS.ZS [Accessed 27 Jun 2020].

45 The World Bank. Physicians (per 1,000 people). Available: https:// data.worldbank.org/indicator/SH.MED.PHYS.ZS [Accessed 27 Jun 2020]

46 Society of Critical Care Medicine (SCCM). United States resource availability for COVID-19, 2020. Available: https://sccm.org/Blog/ March-2020/United-States-Resource-Availability-for-COVID-19 [Accessed 27 Jun 2020].

47 Craig J, Kalanxhi E, Osena G. Estimating critical care capacity needs and gaps in Africa during the COVID-19 pandemic. medRxiv 2020.

48 Triggle N. Coronavirus: is the NHS ready for the surge in cases? 2020. Available: https://www.bbc.co.uk/news/health-51714498 [Accessed 27 Jun 2020]

49 Löfgren E. The biggest challenge of our time: how Sweden doubled intensive care capacity amid Covid-19 pandemic, 2020. Available: https://www.thelocal.com/20200623/how-sweden-doubledintensive-care-capacity-to-treat-coronavirus-patients [Accessed 27 Jun 2020].

50 Ping D. The global epidemic is heating up, Yimeiying's respirator is in emergency! Are there enough life-saving tools in Taiwan? 2020 Available: https://www.gvm.com.tw/article/71733 [Accessed 27 Jun 2020].

51350 Ekmo in Korea, 9823 ventilators 87 patients with severe disease, 2020. Available: https://m.medigatenews.com/news/1828716248 [Accessed 27 Jun 2020].
52 Karlsten E. Corona: Så är utgångsläget i sjukvården för Sverige - jämfört med Italien och Spanien, 2020. Available: https:// emanuelkarlsten.se/03/sa-bra-och-daligt-ar-sverige-rustat-forcorona-jamfort-med-italien-och-spanien/ [Accessed 27 Jun 2020].

53 WHO. Current health expenditure $(\mathrm{CHE})$ as a percentage of gross domestic product (GDP) (\%) data by country. Available: https://apps. who.int/gho/data/node.main.GHEDCHEGDPSHA2011 [Accessed 27 Jun 2020].

54 Export.gov. Healthcare resource guide: Taiwan, 2019. Available: https://2016.export.gov/industry/health/healthcareresourceguide/eg_ main_108622.asp [Accessed 27 Jun 2020]

55 The World Bank. GDP, PPP (constant 2017 international \$). Available: https://data.worldbank.org/indicator/NY.GDP.MKTP.PP.KD?end= 2017\&start=1990 [Accessed 27 Jun 2020].

56 Thomala LL. Number of physicians in Taiwan from 2007 to 2018 , 2020. Available: https://www.statista.com/statistics/860217/taiwanphysician-number/ [Accessed 27 Jun 2020].

57 Ministry Of Health Singapore. Ministerial Statement by Mr Gan Kim Yong, Minister for Health, at Parliament on The Second Update on Whole-of-Government Response to COVID-19, 4 May 2020 2020. Available: https://www.moh.gov.sg/news-highlights/details/ ministerial-statement-by-mr-gan-kim-yong-minister-for-healthat-parliament-on-the-second-update-on-whole-of-governmentresponse-to-COVID-19-4-may-2020 [Accessed 27 Jun 2020].

58 Kucharski AJ, Klepac P, Conlan AJK, et al. Effectiveness of isolation, testing, contact tracing, and physical distancing on reducing transmission of SARS-CoV-2 in different settings: a mathematical modelling study. Lancet Infect Dis 2020;20:1151-60.

$59 \mathrm{Ng} \mathrm{Y,} \mathrm{Li} \mathrm{Z,} \mathrm{Chua} \mathrm{YX,} \mathrm{et} \mathrm{al.} \mathrm{Evaluation} \mathrm{of} \mathrm{the} \mathrm{Effectiveness} \mathrm{of}$ Surveillance and Containment Measures for the First 100 Patients with COVID-19 in Singapore - January 2-February 29, 2020. MMWR Morb Mortal Wkly Rep 2020;69:307-11.

60 Hellewell J, Abbott S, Gimma A, et al. Feasibility of controlling COVID-19 outbreaks by isolation of cases and contacts. Lancet Glob Health 2020;8:E488-96.

61 Grassly NC, Pons-Salort M, Parker EPKW. Report 16: role of testing in COVID-19 control. Imperial College COVID-19 response team 2020.

62 Chan-Kyong, P. SCMP.com. Coronavirus: South Korea's infection rate falls without citywide lockdowns like China, Italy, 2020. Available: https://www.scmp.com/week-asia/health-environment/ article/3074469/coronavirus-south-korea-cuts-infection-rate-without [Accessed 26 Jun 2020].

63 Statista. Cumulative downloads of the NHS COVID-19 APP in England and Wales as of December 2020, 2020. Available: https:// www.statista.com/statistics/1190062/covid-19-app-downloads-uk/ [Accessed 3 Mar 2021].

64 Mahtani KR, Heneghan C, Aronson JK. What is the evidence for social distancing during global pandemics? a rapid summary of current knowledge. CEBM, Oxford COVID-19 Evidence Service, 2020.

65 Flaxman S, Mishra S, Gandy A, et al. Estimating the effects of non-pharmaceutical interventions on COVID-19 in Europe. Nature 2020;584:257-61.

66 Zhang Y, Jiang B, Jiamin Y, et al. 'The impact of social distancing and epicentre lockdown on the COVID-19 epidemic on mainland China: A data-driven SEIQR model study'. MedRxiv 2020.

67 Prem K, Liu Y, Russell TW, et al. The effect of control strategies to reduce social mixing on outcomes of the COVID-19 epidemic in Wuhan, China: a modelling study. Lancet Public Health 2020;5:e261-70

68 Islam N, Sharp SJ, Chowell G, et al. Physical distancing interventions and incidence of coronavirus disease 2019: natural experiment in 149 countries. BMJ 2020;370:m2743.

69 Mallapaty S. What the data say about border closures and COVID spread, 2021. Available: https://www.nature.com/articles/d41586020-03605-6 [Accessed 3 Mar 2021].

70 Kelly E, Firth Z. How is COVID-19 changing the use of emergency care, 2020. Available: https://www.health.org.uk/news-andcomment/charts-and-infographics/how-is-covid-19-changing-theuse-of-emergency-care [Accessed 27 Jun 2020].

71 European Society of Cardiology (ESC). Fear of COVID-19 keeping more than half of heart attack patients away from hospitals, 2020. Available: https://www.escardio.org/The-ESC/Press-Office/Pressreleases/Fear-of-COVID-19-keeping-more-than-half-of-heart-attackpatients-away-from-hospitals [Accessed 27 Jun 2020].

72 Markus HS, Brainin M. COVID-19 and stroke-A global world stroke organization perspective. Int J Stroke 2020;15:361-4.

73 PopulationPyramid. Population pyramids of the World from 1950 to 2100. Available: https://www.populationpyramid.net [Accessed 24 Jun 2020]. 
74 WorldPopulationReview.com. Taiwan population. Available: https:// worldpopulationreview.com/countries/taiwan-population/ [Accessed 4 Jun 2020].

75 Kretchmer H. 3 reasons we can't compare countries' coronavirus responses, 2020. Available: https://www.weforum.org/agenda/2020/ 05/compare-coronavirus-reponse-excess-deaths-rates/ [Accessed 26 Jun 2020].

76 Wu SL, Mertens AN, Crider YS. 'Substantial underestimation of SARS-CoV-2 infection in the United States'. Nat Comms 2020;11.

77 StatisticsTimes. List of countries by GDP (PPP) per capita, 2020. Available: http://statisticstimes.com/economy/countries-by-gdpcapita-ppp.php [Accessed 26 Jun 2020].

78 Wolf M. Covid-19 will hit developing countries hard, 2020. Available: https://www.ft.com/content/31eb2686-a982-11ea-a7667c300513fe47 [Accessed 26 Jun 2020]

79 Sung WWY, Kaplan RM. Why do countries COVID-19 death rates vary so much? 2020. Available: https://www.medpagetoday.com/ infectiousdisease/covid19/86527 [Accessed 26 Jun 2020].

80 Zhang LM. Community care facilities for Covid-19 patients with mild symptoms will double bed capacity to 20,000 by end-June, 2020 . Available: https://www.straitstimes.com/singapore/coronaviruscommunity-care-facilities-for-patients-with-mild-symptoms-willhave-bed [Accessed 27 Jun 2020].
81 Romero AM. Singapore: why the Covid-19 infection rate is so high and death rate so low, 2020. Available: https://www.msn.com/ en-sg/news/singapore/singapore-why-the-covid-19-infection-rateis-so-high-and-death-rate-so-low/ar-BB13kPIL [Accessed 28 Jun 2020]

82 ECDC. 2020, 2021 Using face masks in the community. Available: https://www.ecdc.europa.eu/sites/default/files/documents/COVID19-use-face-masks-community.pdf

83 Houreld K, Lewis D, McNeil R. Exclusive: virus exposes gaping holes in Africa's health systems, 2020. Available: https://www.reuters.com/ article/us-health-coronavirus-africa-response-ex/exclusive-virusexposes-gaping-holes-in-africas-health-systems-idUSKBN22J1GZ [Accessed 27 Jun 2020].

84 Walker PGT, Whittaker C, Watson OJ, et al. The impact of COVID-19 and strategies for mitigation and suppression in low- and middleincome countries. Science 2020;369:413-22.

85 Docherty AB, Harrison EM, Green CA. Features of 16,749 hospitalised UK patients with COVID-19 using the ISARIC WHO clinical characterisation protocol. medRxiv 2020.

86 Statistics Times. List of countires by population density, 2020. Available: https://statisticstimes.com/demographics/countries-bypopulation-density.php [Accessed 3 Aug 2021]. 